\title{
Frecuencia del antígeno y aloanticuerpos del sistema Diego en donantes de sangre
}

\author{
Fernando B. Góngora'1,2 y Rosa F. Chiriboga-Ponce ${ }^{3,4}$ \\ ${ }^{1}$ Hemocentro Nacional de la Cruz Roja; ${ }^{2}$ Ministerio de Salud Pública del Ecuador; ${ }^{3}$ Centro de Investigación para la salud en América Latina, Pontificia \\ Universidad Católica del Ecuador; ${ }^{4}$ Facultad de Medicina, Carrera de Bioquímica Clínica, Pontificia Universidad Católica del Ecuador. Quito, Ecuador
}

\begin{abstract}
Resumen
Introducción: El sistema Diego es un sistema sanguíneo irregular involucrado de manera clínica en casos de enfermedad hemolítica del recién nacido y en reacciones postransfusionales, dentro de este sistema de han identificado a 22 antígenos eritrocitarios de los cuales el par $\mathrm{Di}^{\mathrm{a} / \mathrm{D}} \mathrm{i}^{\mathrm{b}}$ son los de mayor importancia por su potencial inmunogénico. Objetivo: Determinar la frecuencia del antígeno Dỉ y la identificación del aloanticuerpo en la población ecuatoriana. Métodos: Se realizó un muestreo aleatorio simple y se testó mediante aglutinación en tubo la presencia o ausencia del antígeno y en metodología en gel la presencia del aloanticuerpo anti-Dí. Resultados: se estableció una prevalencia del antígeno Día del $25 \%$ frente a un 6.09\% de aloinmunización por dicho antígeno en donantes de sangre ecuatorianos; no existieron diferencias significativas en la asociación de las variables, siendo estas independientes de la edad y procedencia del donante, sin embargo se pudo constatar que en Ecuador existe población portadora del antígeno Diego Dí y casos de aloinmunización por este sistema debidos probablemente a la incompatibilidad transfusional sea esta por vía maternofetal o por transfusiones de sangre. Conclusiones y recomendaciones: La distribución de la frecuencia de antígenos y aloanticuerpos del sistema Diego es casi uniforme dentro de la población de nuestro país, probablemente por ser un territorio con alto grado de mestizaje, por lo que es de vital importancia la implementación de la detección de este sistema sanguíneo y su inclusión dentro de los protocolos de detección de anticuerpos irregulares en los bancos de sangre de Ecuador.
\end{abstract}

PALABRAS CLAVE: Sistema Diego. Donantes de sangre. Aloinmunización. Antígeno Dí.

\begin{abstract}
Introduction: The Diego blood group is an irregular blood system which has been involved in cases of hemolytic disease of the newborn and post transfusion reactions, in this system have been identified 22 erythrocyte antigens, among which the pair Di/ $D^{i b}$ is the most important because those have the most immunogenic potential. Objective: This research aims to determine the frequency of antigen $D^{i}$ and their respective alloantibody in the Ecuadorian population. Methods: It was performed a simple random sampling in the donor population, being later tested tube agglutination by the presence or absence of the antigen and its alloantibody Dia applying gel agglutination technique. Results: It was observed an antigen prevalence of $25 \%$ against a $6.09 \%$ of percentage alloimmunization due to $D^{i}$ antigen, without significant differences between men and women and these being independent of the age and origin of the donor, showing that there are some Diego positive cases in Ecuadorian population as probably cases of transfusional alloinmunization or due to fetal-maternal alloinmunization. Conclusions and Recommendations: The
\end{abstract}


frequency distribution of antigens and alloantibodies from the Diego blood group is almost uniform in the population, due presumably to the high incidence of miscegenation in our country. Therefore it becomes vitally important the implementation of this blood system inside the protocols of irregular antibodies identification in Ecuadorian blood banks.

KEY WORDS: Diego system. Blood donors. Alloinmunization. Dỉ antigen.

\section{Introducción}

El antígeno o factor Diego dentro de la clasificación de los grupos sanguíneos ocupa el décimo lugar de descubrimiento entre los antígenos eritrocitarios'. A partir de este hallazgo, realizado por Miguel Layrisse y Tuli Arends, tomó importancia la identificación de este antígeno, realizándose varios estudios principalmente en grupos indígenas de población venezolana y caribeña y encontrándose una frecuencia del $35.54 \%$, esto puso en alerta a los países latinoamericanos de la existencia de un nuevo antígeno eritrocitario capaz de provocar la producción de anticuerpos que ocasionan una enfermedad hemolítica del recién nacido $(\text { EHRN) })^{1,2}$.

Estudios posteriores demostraron que el antígeno Diego $\mathrm{Di}^{\mathrm{a}}$, a pesar de presentar una baja incidencia en la población caucásica, puede producir aloinmunización y desarrollo de anticuerpos anti-Dia que ocasionan reacciones hemolíticas postransfusionales ${ }^{3}$. Una de las características particulares de este anticuerpo es que puede estar presente como una respuesta inmunitaria o de forma natural y ocasionar una reacción hemolítica inmediata.

Muchas veces la aloinmunización por antígenos eritrocitarios del sistema Diego pasa desapercibida, y no es hasta que se presenten reacciones transfusionales o hemólisis fatales en neonatos cuando se determina su existencia en los pacientes involucrados, abriendo así la duda sobre qué porcentaje de la población se encuentra expuesta a estos antígenos de manera desconocida ${ }^{3-5}$.

En Ecuador, la información de la presencia de antígenos y aloanticuerpos del sistema Diego se desconoce, y más aún cuando se trata sobre estudios de prevalencia de dicho sistema, sobre la cual la información resulta casi inexistente. De la misma manera, se desconoce la incidencia de casos de EHRN causada por sistemas sanguíneos irregulares, por lo que cabe la interrogante sobre la frecuencia con que se presenta este sistema sanguíneo en el país, tomando en cuenta que la población no es diferente de manera significativa ni antropológicamente del resto de la población latina del continente. Adicionalmente, en el campo transfusional se ha dado mayor importancia a las reacciones producidas por antígenos del sistema ABO y Rh, dejando de lado de manera errónea las reacciones producidas por antígenos irregulares, entre ellos los del sistema Diego ${ }^{6,7}$.

Todas las investigaciones relacionadas con este antígeno proporcionan las bases científicas para la inclusión de su identificación en las pruebas ordinarias de tipificación sanguínea y las pretransfusionales, especialmente en poblaciones con prevalencias significativas y población indígena. En Ecuador, el Instituto Nacional de Estadística y Censos (INEC) establece que existe una elevada incidencia de población indígena (aproximadamente un millón de habitantes), lo que determina que el $7 \%$ de la población es considerada como población étnica ${ }^{8}$; por lo tanto debe ser considerada la detección sistemática del antígeno Diego, especialmente en mujeres en edad fértil y antes de una transfusión sanguínea.

\section{Métodos}

Se realizó un estudio descriptivo, observacional y de corte transversal con un muestreo aleatorio simple tanto para la determinación de antígenos Dia como de aloanticuerpos anti-Dia. Obtención de las muestras: se utilizaron los tubos pilotos obtenidos durante el proceso de donación y mantenidos en la seroteca de la estación de triaje del hemocentro. Todos los donantes firmaron un consentimiento informado, en el cual se autorizaba la realización de «todos los exámenes necesarios" antes de la utilización de los hemoderivados (FOS.10). Reactivos utilizados: Bio-Rad ID-Dia (Diego) positivo, suspensión $0.8 \%$, Id. 05980; ID anti-Dia dried-monoclonal,: Bio-Rad albumin 30\% lote $11840 \mathrm{y}$ : Bio-Rad DiaClon Coombs Serum Green, Id. 14060 y tarjetas de Coombs-Gel Grifols Id. 3009280. Procesamiento de las muestras: se utilizó la técnica en tubo y mediante la reacción de aglutinación se determinó la presencia o ausencia del antígeno Dia. Para la detección del aloanticuerpo se utilizó suero y la técnica en gel para una mayor sensibilidad. Análisis estadístico: se llevó un registro en Excel en el que constaron los siguientes datos: código, edad, sexo, procedencia, 
resultados, grupo sanguíneo $\mathrm{SABO}$, antígeno $\mathrm{Di}^{\mathrm{a}}$ y anticuerpos anti-Dia , manteniendo la codificación para el análisis mediante estadística descriptiva, mientras que para la relación entre variables se utilizó la prueba estadística del Chi cuadrado?2.

\section{Resultados}

Se analizaron un total de 383 donantes procedentes de 22 provincias del territorio ecuatoriano, determinándose una prevalencia de antígeno $\mathrm{Di}^{\mathrm{a}}$ del $25 \%$, distribuido en 22 provincias, siendo las provincias de Pichincha, Loja, Manabí y el Oro aquellas con mayor frecuencia de este antígeno; otras provincias de la sierra central que presentaron un prevalencia alta fueron Chimborazo ( $9 \%)$, Tungurahua ( $8 \%$ ) y Cotopaxi (7\%). Sobresale también la provincia de Manabí, con un $10 \%$ (Fig. 1).
La relación entre el antígeno $\mathrm{Di}^{\mathrm{a}}$ y el género de los donantes no fue significativa $(p>0.05)$, identificándose una frecuencia del $35 \%$ en mujeres y del $20 \%$ para hombres.

Se identificó un porcentaje de aloinmunización del $6.09 \%$ en la población de donantes ecuatorianos (para este estudio se incluyeron 18 provincias en muestreo aleatorio). Se encontraron individuos aloinmunizados por antígeno Dia en 12 de las 18 provincias que participaron. Manabí fue la de mayor prevalencia, con un $31.32 \%$ de aloinmunización, seguida de Guayas con un $13.64 \%$ y Los Ríos y Pichincha con $9.09 \%$ respectivamente (Fig. 2).

Existe un mayor porcentaje de aloinmunización en mujeres (6.30\%) que en hombres (5.52\%); esto puede deberse a factores predisponentes como embarazos o transfusiones previas. En relación a la edad se identificó que el anti-Dia se encuentra distribuido en

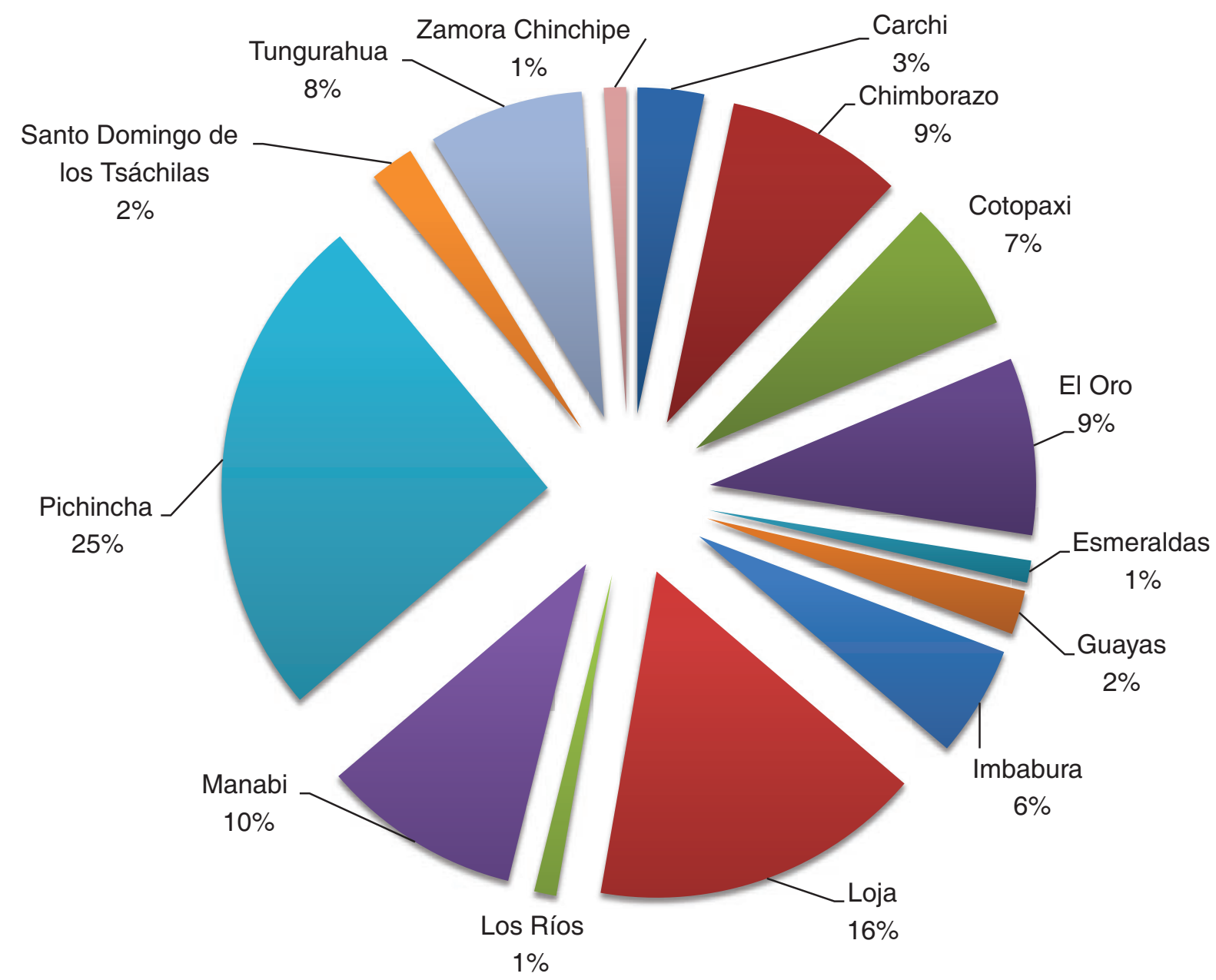

Figura 1. Distribución porcentual del antígenos $D i^{i}$ en donantes de sangre de acuerdo a la procedencia. El gráfico muestra la distribución porcentual de muestras de donantes de sangre de acuerdo a la procedencia. En todas se identificó la existencia de donantes Día positivos. 




Figura 2. Porcentaje de donantes aloinmunizados (anti-Dia) por provincia. El gráfico muestra la distribución porcentual de donantes que presentan el aloanticuerpo Diego, encontrándose que Manabi es la de más alta frecuencia y seis provincias no presentan donantes aloinmunizados.

todos los grupos etarios, sin embargo esta relación de variables no fue significativa $(p>0.05)$.

\section{Discusión}

La prevalencia de los antígenos del sistema Diego, específicamente el antígeno racial $\mathrm{Di}^{\mathrm{a}}$ o $\mathrm{Di}^{1}$, es casi nula en la población afroamericana y caucásica, pero es relativamente frecuente en la población indígena de Latinoamérica ${ }^{3,9}$. En el presente estudio se obtuvo una prevalencia en donantes de sangre ecuatorianos del $25 \%$ de antígeno $\mathrm{Di}^{\mathrm{a}}$, en contraste con el estudio realizado en Guatemala, en el que se estableció una prevalencia total de antígeno Diego $\mathrm{Di}^{1}$ del $7.5 \%$ en donantes de sangre, distribuyéndose la población entre mestiza e indígena y obteniendo una frecuencia del $12.99 \%$ y del $3.90 \%$ respectivamente ${ }^{10}$ : La presente investigación no permite determinar diferencias étnicas debido a que no existe una pregunta que especifique la etnia del donante en el formulario de donación. Sin embargo, de acuerdo al INEC en
Ecuador existe una elevada incidencia de población indígena, aproximadamente un millón de habitantes, lo que determina que el $7 \%$ de la población se considere como población étnica, por lo tanto se podría comprender la elevada prevalencia del antígeno $\mathrm{Di}^{\mathrm{a}}$ encontrada en este estudio. Adicionalmente, dicho porcentaje se encuentra distribuido casi uniformemente por todo el territorio nacional, presentando marcados focos poblacionales en la región sierra 8 . Así, en este estudio se identificó que el $24 \%$ de los donantes con antígeno $\mathrm{Di}^{\mathrm{a}}$ positivo se encuentran en la provincia de Pichincha, seguida de Loja con un $16 \%$, Manabí con un 10\%, además de Chimborazo, Tungurahua y Cotopaxi con una prevalencia de 9, 8 y $7 \%$ respectivamente. Esto corrobora la distribución de este antígeno en las provincias serranas del país, siendo foco importante de la distribución del antígeno Dia la sierra central.

Un dato relevante fue la presencia del $10 \%$ de antígeno Diego en la provincia de Manabí, en la que se identificó un $32 \%$ de aloinmunización por este 
antígeno, dato que muestra la necesidad de incluir pruebas de tipificación para el antígeno Diego en esta provincia. Otros estudios afirman que la frecuencia del antígeno $\mathrm{Di}^{\mathrm{a}}$ puede ser mayor en regiones de América del sur; en la población Kaingangues propia de la región de Santo Domingo, Cabo Verde, en Brasil, la prevalencia asciende hasta el $45.8 \%{ }^{11}$.

La identificación y localización de donantes de sangre portadores del antígeno Diego es de gran utilidad para los bancos de sangre debido a la relación existente entre este antígeno y la producción de anticuerpos causantes de reacciones hemolíticas postransfusionales. El estudio realizado en Guatemala determinó que el $3.5 \%$ de pacientes politransfundidos presentaron anticuerpos anti-Di ${ }^{\mathrm{a}}$. A pesar de no ocasionar una reacción hemolítica severa inmediata, constituye una de las causas de reacciones postransfusionales tempranas, siendo estas de difícil detección, de tal manera que una segunda transfusión incompatible podría ocasionar entonces una reacción hemolítica severa ${ }^{1}$. En este estudio se estableció que la provincia de Pichincha tiene una mayor prevalencia de antígeno $\mathrm{Di}^{\mathrm{a}}$ en relación a las demás provincias, por lo que debe realizarse la identificación de este antígeno por ser el proveedor mayoritario de sangre a los centros de salud del país.

Otro aspecto considerado en esta investigación fue la frecuencia del antígeno Diego $\left(\mathrm{Di}^{\mathrm{a}}\right)$ en relación al género, determinándose una distribución similar entre hombres y mujeres y sus grupos etarios. Estos datos constituyen una información relevante por la probabilidad de aloinmunización en mujeres en edad fértil; a pesar de que existe una prevalencia alta, también existe un porcentaje de mujeres carentes del antígeno, lo que podría ocasionar efectos adversos en una transfusión sanguínea incompatible e inclusive una EHRN. Layrisse, Arends y Domínguez fueron los investigadores que identificaron el primer caso de EHRN, determinando que los eritrocitos del niño se encontraban sensibilizados por anticuerpos anti-Dia provenientes de la madre ${ }^{1,11}$

Posteriormente se estableció que el antígeno Diego, que inicialmente fue considerado de baja prevalencia, se ha convertido en un «marcador de poblaciones mongoloides de gran valor genético y antropológico»'. Varios estudios han establecido que el antígeno Diego forma parte de una proteína de la membrana de los eritrocitos que representa el $25 \%$ del total de proteínas eritrocitarias, es por esta razón que hoy es uno de los antígenos que debe ser identificado en poblaciones con prevalencias altas ${ }^{2}$.
El tamizaje de anticuerpos irregulares o aloanticuerpos en donantes de sangre está dentro de las directrices de los estándares para bancos de sangre ${ }^{12}$, sin embargo las células comerciales utilizadas para este fin no detectan aloanticuerpos del sistema Diego ${ }^{13,14}$, debido a que estas células son preparadas en países donde los antígenos Diego no son comunes, por lo tanto no es posible encontrar células con este fenoti$\mathrm{po}^{2}$. Por ello es necesario introducir estos reactivos en países con prevalencia de estos antígenos. Así, en Singapur el uso de células Dia permitió determinar la presencia de aloinmunización por el sistema Diego en 19 de 1,383 muestras con resultados indeterminados en el panel de células comerciales ${ }^{15}$.

Diversos estudios han determinado la presencia de aloanticuerpos anti-Dia en donantes de sangre, desde el $0.02 \%$ hasta el $13.0 \%{ }^{16}$. En esta investigación se detectó una prevalencia del $6 \%$ de anti-Dia en donantes de sangre, mientras que en Texas en el área de Corpus Christi se reportó una prevalencia del 1.3\% de aloanticuerpo anti-Dia en individuos con transfusiones previas ${ }^{17}$, en Brasil se identificaron 112 (3.6\%) pacientes con anti-Dia, en Singapur se determinó una frecuencia del $1.37 \%^{2,15} \mathrm{y}$ en el estudio realizado en Guatemala se encontró una prevalencia del $3.5 \%$ de anti-Dia en pacientes multitransfundidos ${ }^{10}$. Los anticuerpos anti-Dia son generalmente de tipo Inmunoglobulina (Ig) G1 e IgG3 y está relacionado con enfermedad hemolítica del recién nacido ${ }^{18}$. En un estudio realizado en Brasil se determinó la presencia de anti-Dia en mujeres en un $1.9 \%$, constituyendo un riesgo en caso de embarazo y/o trasfusión sanguínea. En dicho estudio, Marcondones menciona la presencia de dos mujeres sensibilizadas por anti-Dia durante el embarazo; sin embargo los recién nacidos no tuvieron problemas, debido al seguimiento realizado a lo largo del periodo natal. Ello refuerza la necesidad de realizar un tamizaje a mujeres de países con prevalencia de antígenos Diego ${ }^{19}$.

La presencia de anti-Dia está directamente relacionado con reacciones hemolíticas transfusionales, un caso reportado en el año 2012 reportó la presencia de una reacción transfusional en una mujer luego de recibir $800 \mathrm{ml}$ de sangre durante una cirugía; las pruebas pretransfusionales fueron negativas, sin embargo presentó síntomas relacionados a una hemólisis y estudios posteriores identificaron la presencia del aloanticuerpo anti-Di ${ }^{\mathrm{a} 14}$.

Finalmente, la inclusión del sistema Diego dentro de las pruebas de tamizaje de anticuerpos irregulares tanto en donantes de sangre como en pacientes 
multitransfundidos constituye un aspecto emergente debido a las características demográficas de la población ecuatoriana y al porcentaje de aloanticuerpos no identificados que existen en el Hemocentro de la Cruz Roja Ecuatoriana y bancos de sangre que realizan estas pruebas, además de que las células comerciales para tamizaje carecen de estos antígenos. Por lo que una de las recomendaciones al sistema nacional de sangre ecuatoriano es que se prevea cambios en las normativas de seguimiento a mujeres embarazadas dentro del Programa de Maternidad Gratuita, especialmente en aquellas provincias donde se reportaron la existencia de aloanticuerpos del sistema Diego $\left(\mathrm{Di}^{\mathrm{a}}\right)$.

\section{Conflicto de intereses}

Los autores declaran que no existe conflicto de intereses. El financiamiento de esta investigación fue otorgado por la Pontificia Universidad Católica del Ecuador, en su misión de impulsar la investigación entre los docentes.

\section{Bibliografía}

1. Soyano A. El antígeno Diego alcanza los 60 años de edad: su descubrimiento y desarrollo. Gac Méd Caracas. 2014;122(1):46-52.

2. Daniels G. Diego Blood Group Systems. En: Daniels G. Human Blood Groups. 3. ${ }^{\mathrm{a}}$ ed. USA: Wiley-Blackwell; 2013.
3. Park T, Oh SH, Choi CJ, et al. The clinical significance of antibody screening test including Dia+ panel cell in Asian-Mongoloid populations. J korean Med Sci. 2013; 18(5):669-72.

4. Lopez M, Cortina L. Enfermedad hemolítica perinatal. Rev cuba hematol inmunol hemoter. 2000;16(3):161-83.

5. Mun S, Lee $S$. A case of acute hemolytic transfusion reaction due to anti-Dia antibody -A case report. Korean J Anesthesiol. 2012;63(4):353-6

6. Bhutani VK, Zipursky A, Blencowe $\mathrm{H}$, et al. Neonatal hyperbilirubinemia and rhesus disease of the newborn: incidence and impairment estimates for 2010 at regional and global levels. Pediatric Res. 2013;74(Suppl 1):86-100.

7. Marín Rojas RA, Duarte Sibaja MO. Fenotipos y genotipos del sistema Diego en Costa Rica. Rev costarric cienc méd. 1997;18(3):43-5.

8. Resultados del censo 2010 [Internet]. Ecuador: Instituto Nacional de Estadísticas y Censos. Disponible en: http://www.ecuadorencifras.gob. ec/resultados

9. Wei CT, Al-Hassan F, Naim N, et al. Prevalence of Diego blood group antigen and the antibody in three ethnic population groups in Klang valley of Malaysia. Asian J Transfus Sci. 2013;7(1):26-8.

10. Gutiérrez J, Lanz K, Pérez Minera A, et al. Frecuencia del antígeno Dia en donantes y de anticuerpos anti-Dia en pacientes de Hospitales Públicos y del Instituto Guatemalteco de Seguridad Social. Rev argent transfus. 2013;39(4):255-9.

11. Junqueira P. The history of Diego blood group. Rev Bras Hematol Hemoter. 2002;24(1):15-23.

12. Organización Panamericana de la Salud. Estándares de trabajo para servicios de sangre. 3. ${ }^{a}$ ed. Washington: Organización Panamericana de la Salud; 2011.

13. BIO-RAD. Set DiaPanel:45241.45x. DiaPanel. Switzerland, Cressier.

14. Mun SH, Lee SH, No MY. A case of acute hemolytic transfusion reaction due to anti-Di(a) antibody -A case report-. Korean J Anesthesiol. 2012;63(4):353-6.

15. Xian EKC, Y. M. To assess the number of cases of anti-Dia in Singapore and its importance to incorporate into antibody screening panel. Transfusion. 2011;51:136A-7A.

16. Garg N, Sharma T, Singh B. Prevalence of irregular red blood cell antibodies among healthy blood donors in Delhi population. Transfus Apher Sci. 2014;50(3):415-7.

17. Thompson C. Diego(a) antigen frequency and anti-Diego(a) frequency in a South Texas community. Clinical Lab Sci. 2006;19(4):203-5.

18. Daniels G, Bromilow I. Essential Guide to Blood Groups. Oxford: Wiley-Blackwell; 2013.

19. Nardozza LM, Camano L, Fernandes Moron A, et al. Anti-Diego alloimmunization: report of two cases. Arch Gynecol Obstet. 2007;275(6):495-7. 